\title{
La comunicación política: un estudio multidisciplinar desde las ciencias sociales ${ }^{1}$
}

\section{Political communication: a multidisciplinary study from social sciences}

Recibido: 03/06/2019

Aceptado: 15/10/2019

Publicado: 05/12/2019
Néstor-Julián Restrepo-Echavarría nrestr12@eafit.edu.co Universidad EAFIT (Colombia)

Resumen: El objetivo del presente artículo es describir el estudio de la comunicación política, mostrando su evolución teórica historiográficamente. La comunicación política implica pensar en una disciplina que tiene varios enfoques teóricos y escuelas de pensamiento que, desde las ciencias sociales, la política, la comunicación y la sociología, han aportado en la construcción de la comunicación política como una nueva disciplina académica. Por lo tanto, este escrito busca aportar a las discusiones actuales sobre el origen, definiciones y enfoques de análisis sobre la comunicación política, que para muchos es considerada una disciplina ilegitima y trivial, pero que en la actualidad se encuentra en el centro de estudio de las democracias modernas a partir de la notable crisis de representación política, la desafección política, la carencia de ideologías políticas y la alta personalización, así como las nuevas formas de interacción comunicativa que hay entre los ciudadanos y los gobernantes.

Palabras clave: Comunicación política, Democracia, Medios de comunicación, Campañas electorales.

1. El artículo está basado en la tesis doctoral del autor, titulada "La profesionalización de las campañas electorales en Colombia: elecciones presidenciales 1994-2014” (Restrepo-Echavarría, 2018), defendida en la Universidad Complutense de Madrid (España). 
Abstract: The aim of this paper is to describe the study of Political Communication historiographically, showing its theoretical evolution. Political communication involves thinking of a discipline that has several theoretical approaches and schools of thought that, from the social sciences, politics, communication and sociology, have contributed to the construction of political communication as a new academic discipline. Therefore, this paper seeks to contribute to the current discussions on the origin, definitions and approaches to analysis on political communication, which for many is considered an illegitimate and trivial discipline, but which at the moment is in the center of the study of modern democracies from the remarkable crisis of political representation and political disaffection, the lack of political ideologies and high personalization and especially the new forms of communicative interaction between citizens and governments.

Key words: Political communication, Democracy, Media, Electoral campaigns.

\section{Introducción}

Cuando se habla de la comunicación política en general se suele pensar en un fenómeno nuevo, que tendría sus orígenes a inicios del siglo $\mathrm{XX}$, con un papel preponderante desde que la televisión y las nuevas tecnologías de la información, el marketing político ha impuesto todo un método para realizar las campañas electorales, estrategias de comunicación de los gobiernos, legitimando el poder político.

Pero la comunicación política no sólo es una vieja práctica de los grupos humanos, sino que también es uno de los temas más estudiados por diferentes pensadores, ya que la relación entre comunicación y política ha existido desde siempre. Los partidos políticos, los medios de comunicación, los políticos y sus respectivas áreas de competencia, se han ido diferenciado progresivamente, emancipándose y estableciendo, como consecuencia de las nuevas modalidades de determinación y de expresión de las identidades sociales (Mancini, 1995).

Swanson \& Mancini (1996) y Blumler (1999) utilizan el término “democracia centrada en los medios" y entienden que la denominación correcta sería "proceso moderno de divulgación pública" (modern publicity process) que 
son producto de emergencia de una serie de elementos comunes entre la sociedad y los gobiernos que parecen desempeñar un papel clave en el proceso de modernización de la forma de hacer la política y la forma en cómo se concibe la relación entre lo público y lo privado.

Dicha modernización de la política, a través de los medios, se produce por la existencia de una audiencia masiva a nivel internacional, nacional y local, convirtiendo a los mass media en una fuerza de configuración de la opinión pública y en un importante intermedio entre la dirigencia política y el público. Así se produce una dinámica denominada "democracia centrada en los medios" que tiene como característica general la competencia de todos las formas activas de la política: partidos políticos, gobiernos, movimientos sociales y, en general, todo tipo de actor de poder por capitalizar el poder y el lugar central de los medios (en especial la televisión) en la vida moderna: de allí que entre las consecuencias de esta democracia centrada en los medios, se manifiesten fenómenos como la personalización de la política (Swanson \& Mancini, 1996).

\section{En busca de la construcción del concepto de comunicación política}

Se entiende "comunicación" como un intercambio de información, reconociéndose el rasgo distintivo de la comunicación propiamente humana como la capacidad de utilización del lenguaje como sustituto de la realidad, particular a cada cultura y ausente por completo del mundo natural. Desde un acercamiento etimológico, la noción de comunicación, proviene del latín comunicare que significa "hacer común”, por lo que, para Martín-Barbero (2005) es:

[...] hablar de procesos cargados de sentidos profundamente antagónicos. Toda vez que la comunicación significa hoy el espacio de punta de la modernización, el motor de las transformaciones culturales que nos hacen contemporáneos del futuro y está asociada al desarrollo de alcanzar el fin de la definitiva modernización industrial, de la eficiencia administrativa, de las innovaciones educativas y hasta del avance democrático que entrañarían las virtudes descentralizadoras de la informática (Martín-Barbero, 2005).

La comunicación es un proceso activo que permite a las personas, a través de referentes comunes, hacer construcciones colectivas para el desarrollo de 
la sociedad. Del mismo modo, la comunicación (como proceso generador de una serie de relaciones) posibilita la convivencia, el intercambio y la búsqueda de sentidos; es un espacio para la interacción humana, es la constitución y constitutivo de lo humano. Así también, se puede decir que la comunicación determina el proceso de toma de decisiones, en el sentido de que la adopción de medidas necesita de información y de un intercambio de opiniones, signos, señales y símbolos entre aquellos que están implicados (Vallejo, 2009).

De otro lado, la política hace referencia al arte de gobernar y administrar el poder. La política se puede entender como un saber práctico que se realiza con la ejecución de unos principios. Canel (2006) afirma que la política es una actividad que consiste, esencialmente, en la toma de decisiones que incluyen proyectos, planes y programas de acción. Igualmente, indica que la política es el asunto de las cosas públicas, la dirección de las personas y de la comunidad en general.

En este contexto, es esencial entender la relación entre la comunicación y la política a partir de la idea de la esfera pública tal como lo plantea Arendt (1969) y Habermas (1981), quienes ven en lo público la base del proceso de construcción de la democracia, de la gestión del control del poder, de la representación de la voluntad popular, de la discusión y la opinión pública. Lo público viene del latín publicus y se refiere a lo que es notorio y sabido por todos.

Para Ferry \& Wolton (1992) "lo público es un lugar de intercambio de las ideas, pasiones, visiones, espacios, imágenes, intereses y actos que desfilan como un mar de representaciones, heterogéneas y hasta irracionales". Dicha reflexión de lo público estructura la concepción del régimen político democrático y la interrelación que se establece entre el Estado y los ciudadanos a partir del debate público. Asimismo, a partir de la esfera de lo público, se desprende también la idea de opinión pública que se expresa como un conjunto de opiniones sobre asuntos controvertidos o el poder institucionalizado que cuida que las costumbres no se corrompan, que expresen la voluntad general y el juicio público (Noelle-Neumann, 1995).

Pero es Habermas (1981) quien plantea (desde sus estudios de la opinión pública) la relación significativa entre los gobernantes y los gobernados, estableciendo los límites y alcances de los derechos ciudadanos, del diálogo polí- 
tico y de la relación entre la opinión pública y el régimen democrático a partir de la legitimación de los procesos públicos. La relación entre los ciudadanos y los gobernantes se va convirtiendo en el rasgo fundamental de la comunicación política en el régimen democrático, en el que se establece un intercambio de símbolos y signos para conquistar el poder, mediante la dialéctica entre ambos actores que se hace posible en un entorno de libertad y de ausencia de coerción. Por lo tanto, cuando se habla de la comunicación política se suele pensar en un fenómeno nuevo que tendría sus orígenes a inicios del siglo XX y que tiene un papel preponderante desde que la televisión y las concepciones del marketing político impusieron todo un método para realizar las campañas electorales.

Para Gerstlé (2005) la comunicación política es un objeto de estudio de difícil aprehensión, porque se apoya en conceptos que ya están sobrecargados de sentido; sus relaciones son naturalmente problemáticas y sus manifestaciones multidimensionales. Además, establece que lo que ahora se llama "comunicación política" es un ámbito de contornos muy inciertos según se consideren como un conjunto de teorías, de técnicas o de prácticas. Para el autor, la comunicación política es un saber que se caracteriza por ser interdisciplinario y por la diversidad de enfoques que tiene debido a la transversalidad de los problemas planteados (Gerstlé, 2005). Ciencias como la sociología, la lingüística, la semiótica, la antropología, el derecho, la historia, la sicología, la filosofía y finalmente, la ciencia de la información y la ciencia política, establecen una serie de preguntas propias desde su saber específico para construir el paradigma de la comunicación política, convirtiéndolo en una disciplina polisémica.

Para Cotteret (1997), la comunicación política establece la interacción voluntaria de un mensaje político desde el emisor hasta el receptor, con la intención de arrastrar a quien lo recibe hacia una dirección determinada, de tal manera que no pueda encaminarse hacia otra. Además, define una función clara de la comunicación política como un intercambio de información entre los gobernantes y los gobernados, a través de los canales de transmisión estructurados o informales. Del mismo modo, Canel (2006) considera la comunicación política como una función básica que, en cierto modo, controla y hace posibles las demás funciones del sistema político a partir de la información que circula en este, desde la formación de las demandas hasta los procesos de conversión y las respuestas del sistema. 
Wolton (2012) sostiene que la comunicación política es un fenómeno específicamente moderno que se ha ido desarrollando desde hace más de doscientos años como consecuencia de la creciente democratización en los sistemas políticos y las sociedades occidentales. Dicho fenómeno parte de la sociedad política realmente existente, que está organizada en forma de una "democracia parlamentaria homologada", es decir, una sociedad en la cual el pueblo está organizado en partidos. En este escenario, quienes detentan el poder o aspiran a él (los partidos y los ciudadanos que giran en torno a estos) se valen de la comunicación, cuyo propósito es conservar el poder o conseguirlo. Por lo tanto, es esencial atraer por medio de la persuasión a los ciudadanos hacia un partido y rechazar a los adversarios.

Para Restrepo-Echavarría (2018), Bouza (2004), Canel (2006), Chaffee (1981) y Blake \& Haroldsen (1975), la comunicación política fue inicialmente una ciencia de los medios de comunicación y sus efectos aplicados sobre la política. Como ciencia, tiene sus principales referencias en la literatura científica de conjunto con las ciencias sociales: sus reflexiones y enunciados siguen la tradición metodológica de dichas ciencias.

Desde lo profesional, la comunicación política incluye una serie de fenómenos comunicativos que han recibido una serie de etiquetas como: propaganda política, relaciones públicas o comunicación institucional política, que tiene una función mediadora mediante la cual se movilizan y transmiten las influencias políticas entre unas instituciones gubernamentales formales y el ciudadano- votante. Por lo tanto, la comunicación política posibilita que exista un intercambio entre las instituciones y el público, permite establecer vínculos entre las instituciones mismas, legitimar proyectos, justificar acciones, explicar los planes de gobierno y mostrar sus objetivos, justificar sus acciones y sustancialmente lograr el apoyo de los ciudadanos (García, D’Adamo \& Slavisky, 2011).

De igual forma, no es exclusiva en momentos electorales, pues también se encuentra la comunicación política de gobierno que ha sido definida como el proceso de influencia intencional que un gobierno intenta realizar sobre la opinión pública, la prensa, la oposición, los legisladores, así como todos los grupos y actores políticos y sociales, con el objetivo de volver más eficiente la gestión política (García, D’Adamo \& Slavisky, 2011). 


\section{Comienzos y desarrollo de la comunicación política}

La comunicación política tiene sus inicios en Grecia y en la filosofía griega, donde se empieza a reflexionar sobre el poder, la autoridad, la persuasión y la retórica, bajo la idea del debate de la democracia. En efecto, el origen de la comunicación política en Grecia se puede asociar con el poder de la retórica. En la segunda mitad del siglo V a. C., aparecen los sofistas ${ }^{2}$, quienes fueron los precursores de la enseñanza pragmática, con un fin que iba más allá del puro conocimiento intelectual.

Estos trabajaban pensando básicamente en sus contemporáneos, en las observaciones de los diferentes procesos sociales y políticos, sin profundizar en la razón de las cosas, ni tras la búsqueda de la verdad. Su valor principal era la elocuencia y la persuasión como algo que podría ayudar a lograr un objetivo político, donde ellos veían la posibilidad de enseñar y aprender a persuadir a un individuo o a un grupo determinado (Martín, 2002).

Gorgias (487 a. C.) es uno de los grandes exponentes de este grupo, quien usa la retórica en Atenas como respuesta a la necesidad de argumentar ante los tribunales. A partir de esto, la retórica se fue convirtiendo sistemáticamente en una técnica de persuasión que podía utilizarse en el campo político. Dicha técnica se iba alimentado en la ciudad-Estado a partir de los cambios que se iban experimentado en materia política y cultural: el paso de un sistema aristocrático a uno democrático, un cambio en la forma de vida y de gobierno en la ciudad-Estado y finalmente la aparición de nuevos modelos de educación que hacen que las interacciones entre los ciudadanos cambien a partir de la democratización de su sociedad y, por lo tanto, tuvieran que depender (en mayor medida) del discurso y la persuasión (Caballero, De Echano, Martínez, Montarelo \& Navlet, 2001).

Pero es Aristóteles quien elabora todo un tratado sobre la retórica. Para este filósofo, la retórica es un "arte", una tékhne, un tratado teórico-práctico sobre un objeto concreto, en este caso la palabra persuasiva, el discurso retórico. Es decir, es un conjunto sistemático de conocimientos universales teórico-prácticos que rebasa el nivel de la mera experiencia (Caballero, De Echano, Martínez, Montarelo \& Navlet, 2001).

2. Alude principalmente para distinguir, en sentido genérico, a las personas que tenían el significado de sabiduría, eran destacados en cualquier saber, ya sea, teórico o práctico. 
En concreto, Aristóteles describió la retórica como un análisis amoral de los medios de persuasión, creyendo que era necesario como instrumento político y con la convicción que tanto el pensador (que conozca sus técnicas) como la multitud se beneficiarían, poniendo en común su sabiduría para guiar al Estado (Martín, 2002). Además, defendió la obligación de ser persuasivo, sobre todo para debatir temas de la democracia que no se puede demostrar de manera absoluta, como la obligación de conocer cómo funciona la persuasión, porque era el conocimiento de la retórica lo que ayudaría a los ciudadanos a reconocer y distinguir los argumentos justos e injustos (Martín, 2002). Según Aristóteles, la retórica

[...] es útil porque por naturaleza la verdad y la justicia son más fuertes que sus contrarios, de modo que si los juicios no establecen como se debe, será forzoso que sean por dichos contrarios, lo cual es digno de recriminación, además de que, en lo que toca a algunas gentes, ni aun si dispusiéramos de la ciencia más exacta, resultaría fácil, argumentando sólo con ella, lograr persuadirlos, pues el discurso científico es propio de la docencia, lo que es imposible en nuestro caso, y más bien se necesita que las pruebas por persuasión y razonamiento se compongan por medio de nociones comunes. Por lo demás conviene que sea capaz de persuadir sobre cosas contrarias, como también sucede en los silogismos, no para hacerlas ambas (pues no se debe persuadir de lo malo), sino para que no se nos oculte cómo se hace y para que, si alguien utiliza injustamente los argumentos, nos sea posible refutarlos con sus mismos términos (Aristóteles, 2004).

\section{Aristóteles planteaba que}

[...] el hombre es doblemente definido como animal social y como animal dotado de lenguaje, es decir, de capacidad simbólica. Estas propiedades esenciales reciben su creación institucional en las reglas centrales de la polis que estimulan la participación en los asuntos públicos. Cada ciudadano tiene igual derecho a tomar la palabra en la asamblea, donde puede, por otra parte, hablar libremente, ya que la retórica está facultada en teorizar lo que es adecuado en cada caso para convencer (Aristóteles, 2004).

Pero es en Roma, durante el periodo de la República, cuando gobiernan los magistrados elegidos por la ciudadanía, donde se evidencia la construcción de la disciplina de la comunicación política, trascendiendo de la retórica hacia las primeras propuestas publicitarias y consultorías políticas. Un buen exponente de este periodo es Quinto Tulio Cicerón, con su texto Breviario de 
campaña, en el que ejerció el rol de asesor de campaña de la candidatura de su hermano Marco Tulio hacia el Consulado de la República Romana, cargo que desplegaba la máxima autoridad militar y civil de aquella época (más de veinte siglos atrás). En la contienda electoral, Marco Tulio se enfrentó a seis adversarios políticos, de los cuales dos representaban una real competencia. Sin embargo, este resultó ganador (al igual que Gayo Antonio Híbrida) gracias a las tácticas y estrategias políticas ejecutadas por su hermano Quinto: despertar simpatía entre las altas esferas de la sociedad es beneficioso para la campaña, así como conquistar el voto de los indecisos, conocer la reputación y antecedentes de los oponentes.

Si pones en práctica lo que te ha concedido la naturaleza y el estudio, y de lo que siempre te has valido, si haces lo que las circunstancias exigen de ti, lo que puedes y lo que debes, no te será difícil hacer frente a estos rivales cuya fama está llena de vicios (Cicerón, 2014).

Para Mazzoleni (2010), en la Antigua Roma se evidenció un sinnúmero de elecciones que se celebraban tanto en la ciudad-Estado como en las provincias cercanas y que incluían sofisticadas técnicas de comunicación en las campañas electorales, donde se mezclaban las reglas de la retórica con las artes persuasivas del clientelismo propio de la tradición romana. En ciudades como Pompeya se evidenciaban carteles y eslóganes que invitaban a votar o tenían mensajes negativos en contra de un candidato, se realizaban propagandas orales en calles y plazas, con el propósito de tener contacto directo entre los candidatos, probablemente versados en el arte de la oratoria, con el pueblo de los electores (Mazzoleni, 2010).

Las estrategias y formas de hacer campañas electorales en Roma se convierten en el referente de un tipo de comunicación política, que se estructura como una forma de lenguaje político en el que se aplican técnicas para crear una extensa red de control, tanto en el momento de una elección política como en el día a día de un gobernante. Por ejemplo, los emperadores se valieron de todos los medios de comunicación disponibles de ese entonces para mantener sus gobiernos fuertes y centralizados: destinaron numerosos recursos para simbolizar las glorias mediante la arquitectura, el arte, la literatura y la imposición de una moneda.

En este rastreo historiográfico, es importante precisar la aparición de la propaganda como elemento sustancial del estudio de la comunicación política y como una 
forma de control sistemático y de manipulación de la cultura y de la información en las relaciones de poder que se establecen entre los gobernantes, la aristocracia, el clero y el pueblo en general. Para Lasswell (1938), la propaganda es "la expresión de una opinión o una acción por individuos o grupos, deliberadamente orientada a influir opiniones o acciones de otros individuos o grupos para unos fines predeterminados y por medio de manipulaciones psicológicas".

Desde la Edad Media, el cristianismo favoreció la difusión de su doctrina utilizando fórmulas de propaganda, tales como el recurso de líderes carismáticos y los fuertes simbolismos que permitieron difundir el mensaje con poderoso acento emocional y de fácil comprensión (García, D’Adamo \& Slavisky, 2011). Más adelante, en el siglo XV, apareció la imprenta de tipos móviles, como un desarrollo tecnológico en la difusión comunicativa, que cambió sustancialmente la forma de la comunicación.

En efecto, Martín Lutero empleó dicho recurso durante la reforma protestante en su lucha de poder, cuando enfrentó a la Iglesia Católica Romana. Posteriormente, en el Renacimiento, apareció una obra fundamental como punto de inflexión de la estrategia comunicativa en la política que es El príncipe, de Maquiavelo (1513), que contiene algunas reglas, estrategias y principios comunicativos para trabajar asuntos como la imagen del gobernante.

En el siglo XVIII y XIX, tiempos de profundas revoluciones y marcada agitación política, había mejorado considerablemente tanto la tecnología de la imprenta como la eficiencia y velocidad del transporte, lo que hizo posible diseminar los mensajes hacia audiencias más amplias. Los periódicos se convirtieron en poderosos vehículos para la difusión de información propagandística. Además, se comenzaron a utilizar las caricaturas políticas y los afiches políticos, que paulatinamente se volvieron un medio de comunicación común que abrió paso a todo un nuevo lenguaje visual que se intensificó durante la independencia de los Estados Unidos, la promulgación de la Constitución y la Revolución Francesa. Es hasta el nacimiento de las ideas liberales y democráticas donde se vuelve a encontrar el ejercicio de formas de comunicación política durante las elecciones (o fuera de ellas), con un periodismo libre de la censura de los regímenes absolutos (Mazzoleni, 2010).

Desde el siglo XX, a partir del principio de la democracia electoral, es donde se ha adoptado el término de comunicación política en sentido pleno. Son los 
medios de comunicación y las nuevas tecnologías de la información los que crearon las condiciones para el desarrollo y la maduración de las técnicas de la comunicación al servicio de la esfera política (Mazzoleni, 2010).

Estados Unidos y su sistema político se convierten en el mayor laboratorio de la comunicación política en el mundo, debido a la estabilidad de sus gobiernos e instituciones, las amplias garantías al sistema de información y la posibilidad permanente de realizar elecciones libres en todas las esferas del poder. En efecto, Pasquino (1990) evidencia, mediante el análisis de las campañas electorales en Norteamérica, la evolución en la comunicación política. Al respecto, argumenta que en Estados Unidos los medios de comunicación han cambiado, de manera más contundente que en otros lugares del mundo, el modo de hacer la política. Asimismo, valora la extensa literatura que se ha desarrollado sobre la evolución de los procesos electorales en Estados Unidos y su importancia para comprender dicho cambio.

\section{La función de los medios masivos de comunicación en la comuni- cación política}

En el desarrollo de la comunicación política, los medios de comunicación son fundamentales en tanto permiten persuadir al electorado a través de un conjunto de mensajes e imágenes. Para Pasquino (1990), la incursión de los medios masivos de comunicación (en particular la televisión) en la escena política, ha originado un espectáculo que establece un cambio en las relaciones entre el liderazgo político y la comunicación política, que modifican las interacciones entre los líderes políticos y sus electores, así como entre las organizaciones sociales y representativas, los partidos políticos, los sindicatos, entre otros. De igual manera, la incorporación de los medios masivos de comunicación en la política permite la aparición de la personalización del liderazgo político, en el que la personalidad del hombre y de la mujer en la política se construye de manera individual, dejando de lado la institucionalidad política. En este contexto, la comunicación política actúa como una lupa que acentúa al individuo político. Quevedo, citado por Restrepo-Echavarría (2018), argumenta que el ciudadano sufrió una transición muy marcada en la forma de interpretar la política, migrando de la política de la plaza pública hacia la televisión. 
Por su parte, Debray (1995) indica que lo más importante para persuadir a un elector es la imagen pública de un candidato a partir de la televisión, por lo que ahora la imagen televisiva puede convencer más que la propia realidad. A lo anterior, Sartori (1998 y 2005) lo ha denominado "videopolítica", la cual se centra en los candidatos y es orientada hacia la televisión que es el escenario principal de los eventos de campaña, lo que establece nuevas formas de difundir el mensaje político basada en la imagen pública. De esta manera, la televisión se convierte en el mayor depósito de ideas, datos y consensos que nutren a los ciudadanos y les ayuda a construir un interés político, a opinar sobre una coyuntura determinada y a discernir sobre un candidato en el momento de la votación.

Como consecuencia de los adelantos técnicos en las nuevas tecnologías de la información, aparece la comunicación digital, configurando un nuevo modelo de interacción pública entre el político y el elector, que se caracteriza por ser más técnico y en el que ambos agentes tienen la capacidad de segmentar las opciones, de acuerdo con sus intereses personales e ideológicos. En efecto, la intervención de la Internet en el escenario político ha transformado el proceso de modernización de las campañas electorales, las cuales han avanzado hacia el ciberespacio (web 2.0) que ha ocupado el terreno de la plaza pública y en el que el debate no versa sólo sobre los asuntos que los partidos consideran prioritarios, sino cada vez más sobre los que plantea la sociedad civil en el escenario virtual (Cotarelo, 2010).

Considerando lo anterior, se puede evidenciar la influencia que tienen los medios masivos de comunicación sobre la política y, de manera particular, en las instancias electorales. En efecto, Fernández, citado por Abal (2004), sostiene que "a medida que la comunicación se hace más compleja, los medios de comunicación podrían estar en la vía de sustituir a los partidos políticos en su relación con la gente".

En este sentido, se argumenta que los medios de comunicación lideran las relaciones entre el ciudadano y el Estado, transformándose en el intermediario por excelencia que interpreta las demandas y los intereses de la gente. Finalmente, las tecnologías de la información y la comunicación (TIC) en la política, han permitido minimizar las limitaciones de tiempo y distancia que pueden afectar a la participación política, disminuyendo los costos de organización partidaria y aumentando la comunicación interpersonal mediante el intercambio de contenidos entre los gobernantes y los gobernados. 


\section{Los enfoques de comunicación política}

Con el propósito de abordar un panorama general de las investigaciones realizadas sobre la comunicación política, sus efectos y planteamientos fundamentales, así como sus autores y las obras más conocidas, se toman en cuenta cuatro corrientes: a) teoría de la propaganda (1920-1940), b) escuela de Columbia o de los "efectos mínimos", c) Escuela de Michigan o de la "identificación partidista" y d) escuela de los "efectos cognitivos" y la vuelta a la concepción poderosa de los medios (Restrepo-Echavarría, 2018).

\subsection{Teoría de la propaganda (1920-1940)}

Este modelo propagandístico establece la comunicación política a partir de la interacción que constituyen los actores del escenario político como son las instituciones políticas, los medios de comunicación y los ciudadanos. Lippmann (2003) y Lasswell (1938) son quienes introducen sus estudios en este modelo propagandístico, en el que se encuadra la definición de comunicación política en un contexto dinámico y racional entre los actores.

Desde estos estudios, surge la teoría de la "aguja hipodérmica" o de la "bala mágica", refiriéndose al impacto que los medios de comunicación ejercen sobre el público atomizado y proclive a caer bajo la persuasión de la propaganda, que resulta efectiva cuando logra la adhesión de las masas sin aparente violencia ni corrupción del emisor.

Los medios de comunicación son fundamentales para esta teoría como instrumentos idóneos que permiten alcanzar todo propósito con fines de control social masivo. La audiencia será, a partir de entonces, "el blanco de la bala mágica", lanzada bajo la magia de la fórmula conductista del estímulo-respuesta (Figueroa, 2013).

Lasswell (1938) abordó la influencia de la propaganda, la opinión pública y la vida de los líderes reformadores, aplicando conceptos de la sicología clínica al estudio de los actores políticos, económicos y religiosos, como es el caso de los gobiernos totalitarios de principios del siglo XX en Europa. Asimismo, postula que todo proceso de comunicación de masas cumple con tres funciones sociales: primero, la vigilancia o supervisión del ambiente, como por 
ejemplo la función informativa de la prensa; segundo, la concordancia de las partes de la sociedad en respuesta a ese ambiente, por ejemplo, el efecto que produce sobre la actitud de las personas los mismos medios de comunicación; y tercero, la limitación del poder de los medios afectando al público en pequeña medida (Figueroa, 2013).

La "teoría hipodérmica" es propuesta en 1948 por Lasswell y explica que una forma apropiada para describir un acto de comunicación es respondiendo las siguientes preguntas: ¿quién dice qué?, ¿a través de qué canal?, ¿a quién? y ¿con qué efecto? Cada una de estas variantes busca definir, dentro de la investigación, tres aspectos: el primero, es el estudio de los emisores y el control sobre lo que es difundido; el segundo aspecto, es el análisis de la elaboración del mensaje y finalmente, el tercero, es el estudio de los elementos que dan lugar al análisis de los medios.

La fórmula de Lasswell busca generar unas premisas para los procesos comunicativos de masas $^{3}$. En concreto, dichos procesos comunicativos son asimétricos, con un emisor activo que produce estímulos y una masa pasiva de destinarios que reacciona cuando es atacada por el estímulo. Además, la comunicación es intencional y tiene como objetivo lograr un efecto que es mesurable en cuanto da lugar a un comportamiento que genera dos consecuencias: el análisis del contenido que se propone y el instrumento de manipulación de los emisores (Figueroa, 2013).

\subsection{Escuela de Columbia o de los "efectos mínimos"}

Esta escuela corresponde a la primera generación de los llamados "estudios electorales clásicos" que están representados por las obras como las de Lazarsfeld, Berelson \& Gaudet (1944) y de Lazarsfeld, Berelson \& McPhee (1954), que tenían como propósito abordar el índice de predisposición política que viene dado por factores sociales como la filiación religiosa, la situación económica, el lugar de residencia, el partido al que se vota, el grupo social al que pertenece, entre otros (Berrocal, 1993).

3. Según Rocha (2007), la teoría no encaja con la realidad, pues para que la teoría de la aguja hipodérmica funcione los mensajes deberían llegar de modo uniforme a los destinatarios, provocando reacciones iguales: no todas las personas están expuestas a los medios, ni tampoco de la misma forma. 
Lazarsfeld, Berelson \& Gaudet (1944) estructuran una nueva forma de ver las campañas electorales a partir de las elecciones de 1940 en Estados Unidos y que se convirtieron en el centro del primer estudio de panel. Esta investigación tenía el objetivo de medir la propaganda y el cambio de intención de voto de los electores en los Estados Unidos, señalando los efectos de la comunicación en el individuo y en la sociedad a través de las preguntas: ¿quién dice qué?, ¿a quién? y ¿con qué efecto? La obra trata de reconocer parcialmente la importancia de la influencia personal de unos votantes sobre otros y resolver el problema del papel político que juegan los temas de campaña. El estudio está organizado en dos partes: la social y la política. La primera, está dedicada al estudio de la formación de categorías de análisis y la segunda al comportamiento del electorado.

Lazarsfeld, Berelson \& Gaudet (1944) muestran las pautas de la comunicación política que se va fortaleciendo como disciplina a partir de un cambio sustancial en el entorno de los Estados Unidos. Lo primero es que existe una predisposición política que viene dada por factores sociales y segundo, que las personas que se exponen a los medios de comunicación suelen ser aquellas que ya tienen unas opiniones y filiaciones políticas bien establecidas. Los menos firmes y, por tanto, teóricamente más susceptibles a las influencias, son los menos proclives a ser alcanzados a través de los medios de comunicación. Los autores establecen que las personas tienden a exponerse al bando con el que de todos modos ya está de acuerdo:

Es el nivel socioeconómico y la educación los que afectan los intereses en la elección. Los votantes pobres, no educados muestran los niveles más bajos de interés, y los más prósperos y educados muestran los más altos. Los dos grupos del medio revelan que el nivel socioeconómico y la educación tienen casi la misma influencia sobre el interés en la elección (Lazarsfeld, Berelson \& Gaudet, 1944).

Lazarsfeld, Berelson \& Gaudet (1944) argumentan que las personas son libres de elegir entre las opciones políticas que se presenten y, por lo tanto, los medios masivos de comunicación inciden muy poco en el resultado de las elecciones. Afirman que la propaganda no influye sobre la voluntad de los individuos, es decir, no la modela ni la construye. Por lo tanto, las campañas electorales se ven como un periodo de tiempo donde, según ellos, los individuos han de tomar decisiones políticas. En definitiva, las elecciones quedan 
decididas por acontecimientos que dan lugar en todo el periodo comprendido entre las dos elecciones presidenciales y no por la campaña.

Lazarsfeld, Berelson \& Gaudet (1944) sostiene que mientras “más interesada está la gente en las elecciones, más opiniones tienen sobre cuestiones políticas, más activamente participan en una campaña y más se exponen ellos mismos a la propaganda de campaña". Concluyen que la propaganda refuerza la intención de voto de los electores que ya han tomado su decisión antes de comenzar la campaña y activa las predisposiciones latentes de la mayoría de los que se encuentran indecisos (Berrocal, 1993). Los autores proponen el estudio de la influencia que tienen los líderes con sus seguidores a partir de la persuasión discursiva "cara a cara", donde el líder es fundamental, ya que genera y legitima la opinión y son los que transmiten la información al resto de la población.

Más tarde, Lazarsfeld, Berelson \& McPhee (1954) realizaron un estudio en marco de la campaña presidencial de los candidatos Harry Truman y Thomas Dewey en 1948, cuyo propósito era abordar la idea inicial de analizar los efectos de los medios de comunicación en la campaña y la opinión pública. Los autores concluyeron que las personas con alto nivel de formación académica son las que mayor probabilidad tienen de no cambiar de partido y las que con mayor probabilidad emitirán su voto.

En general, para los estudios de los efectos mínimos, el comportamiento de los electores se origina, principalmente, en el hecho de que los votantes con fuertes identidades políticas y un elevado interés en la campaña electoral, son quienes reciben la mayor proporción de mensajes políticos. Estos electores con organizaciones políticas que tienen bases sociales se exponen, en mayor medida, a las fuentes de información política que opinan sobre los temas de campaña con un conocimiento más amplio y que participan intensamente en los eventos electorales, concentrando su atención en las expresiones comunicativas de las opciones políticas que defienden (Dahdah, 2004).

No obstante, no todo es nulo y desestimable, pues la propaganda puede ser concebida como una herramienta importante para la formación de la imagen del candidato. Su objetivo principal está en la construcción de las candidaturas en términos de alternativas políticas claramente discernibles. Finalmente, para los estudios de Columbia son tres los efectos producidos 
por la comunicación política: activación, refuerzo y conversión. El primero, se refiere a la activación de las predisposiciones latentes; el segundo, intenta reforzar las predisposiciones y el tercero, busca la conversión de las opiniones contrarias.

\subsection{Escuela de Michigan o de la "identificación partidista"}

Esta escuela defiende la idea que la política no es importante en la vida de la gente y que la identificación partidista es forjada en bases afectivas a lo largo del proceso de socialización, funcionando como soporte de resistencias a las influencias puntuales. Es decir, el proceso de petición del voto tiene poco efecto, pues son las orientaciones previas de la gente las que orientan las opciones políticas (Rocha, 2007). En consecuencia, esta escuela comparte con la escuela de Columbia el modelo de los "efectos limitados" (Berrocal, 1993).

Campbell, Converse, Miller \& Stokes (1960) se concentran en el análisis de los votos individuales que hacen las personas en las elecciones políticas, a partir de la afectividad partidista y así establecen una aproximación a la sicología social y a los comportamientos de la conducta de la elección individual de los candidatos. Por lo tanto, establecen factores decisivos como son: la evaluación de los entornos políticos, la identificación partidista y un enfoque racional a la hora de la elección. La evaluación del impacto en el comportamiento del mapa político, cognitivo y afectivo del público lo describen en términos de la actitud individual: "votar es al final un acto de individuos y los motivos para este acto deben ser vistos en fuerzas sicológicas sobre seres humanos individuales" (Campbell, Converse, Miller \& Stokes, 1960, p. 64). Además, argumentan que:

los elementos de la política que son visibles para el electorado no son simplemente vistos, también son evaluados. La evaluación es la materia de la vida política y la imagen cognitiva formada por el individuo del mundo político tiende a ser positiva y negativamente enfocado en sus diversas partes. La mezcla de cognición y evaluación, de creencia y actitud, de percepción y afecto es tan completa que se hablará del mapa político, cognitivo y afectivo del individuo (Campbell, Converse, Miller \& Stokes, 1960). 
Campbell, Converse, Miller \& Stokes (1960) enfatizan más en el contenido ideológico de la política, donde expresan que la mayoría de las personas no se adhieren a un conjunto completo de creencias que producen una ideología, ni tienen una comprensión clara de lo que es la ideología. Además, analizan las tendencias ideológicas y la forma en como los ciudadanos entienden las vertientes "liberal-conservador", concluyendo que normalmente las personas de a pie, debido a su inestabilidad y a su estructura de creencias, sólo tienen una gran cantidad de opiniones al azar, incluso en temas muy controvertidos, bien publicitados pero sobre los que al fin las personas no tienen opiniones coherentes.

Como resultado de su investigación, Campbell, Converse, Miller \& Stokes (1960) clasifican los votantes en cinco categorías a partir de su comprensión de la diferenciación ideológica y de su forma de interpretarla: a) los electores "ideólogos" evalúan los objetos políticos y su cambio de significado político a través del tiempo; b) los "cuasi-ideólogos", quienes mencionan la dimensión ideológica liberal-conservadora periféricamente, pero no enfatizan en esta; c) los "grupo de interés" comprenden el espectro ideológico, pero la toma de decisiones depende de la base de los grupos y los partidos políticos que los representan; $d$ ) el grupo que forma parte de la "naturaleza de los tiempos" comprende las diferencias ideológicas entre los partidos políticos, pero toma sus decisiones por la naturaleza de los tiempos y la coyuntura política; y e) los electores sin ningún contenido y que se caracterizan por no importarle la política, aunque por tradición sí se sienten de afiliación partidistas.

En conclusión, esta escuela considera que los medios de comunicación no influyen en los electores ya identificados y su influencia es mínima en los votantes indecisos ya que no están interesados en los mensajes de los medios.

\subsection{Los estudios desde la perspectiva cognitiva}

Desde mediados de 1970 hasta nuestros días se ha desarrollado una nueva fase en la comunicación política, consolidada a través de antiguas y nuevas teorías, que hacen resurgir con fuerza el concepto de la influencia de los medios (Berrocal, 1993). El papel atribuido a las campañas cambia a partir del efecto de los medios de comunicación en los procesos políticos. Con esta perspectiva comienzan las teorías de los efectos cognitivos en las que se esta- 
blece una nueva realidad caracterizada por partidos poco influyentes, electorado sin grandes referentes y centralidad de los medios en la vida política. Tal combinación lleva, de una parte, a los estudios sobre el impacto de los medios $\mathrm{y}$, de otra, a los enfoques de las campañas desde la visión del elector como consumidor, acercando la política a las estrategias del marketing (Berrocal, 1993).

El objetivo del enfoque cognitivo es observar todo el sistema de medios de comunicación y las estrategias a largo plazo, adoptando metodologías integradas y complejas, en conjunto con datos sofisticados, buscando reconstruir el proceso por el cual los individuos cambian su representación de la realidad. Los efectos cognitivos se pueden estudiar desde el acercamiento a las estrategias del marketing comercial implicando la orientación hacia la imagen, donde el candidato se convierte en el producto a ser ofrecido al elector-consumidor. Kotler (1999) aboga por las técnicas comerciales en la política. Dicho estudio parte de una visión de la estrategia, pasando por aspectos de la organización y la toma de los medios de comunicación como soporte fundamental al desarrollo de las estrategias que visualizan a un elector alejado de la política.

De igual manera, Berrocal (1993) enmarca la concepción cognitiva como una fase del desarrollo de la comunicación política, consolidándose por el contraste de las anteriores teorías de la propaganda y las teorías de los efectos mínimos. Esta generación de estudios electorales se mueve en el campo donde los medios de comunicación han adquirido un lugar predominante en la elección y en la toma de decisiones de los votantes con respecto a la elección de los candidatos. Estas teorías se han desarrollado desde tres teorías. La de "usos y gratificaciones" responde a un modelo centrado en la audiencia y que entiende los medios de comunicación de un modo que satisface las necesidades relacionadas con la interacción social. Este modelo toma como punto de partida al consumidor de los medios y explora su conducta comunicativa en función de su experiencia directa con los medios en cuyas formas los seres humanos crean y gratifican las necesidades (Katz, Blumler \& Gurevith, 1974).

Posteriormente, surgen los estudios que abordan los efectos de los medios de comunicación a partir de las teorías de la "espiral del silencio" y la "agenda setting", cuya característica fundamental es analizar la importancia del fenómeno televisivo avalado por sus altos índices de audiencia. Estas teorías estudian la influencia que los medios de comunicación (especialmente 
la televisión) generan sobre las personas, el entorno y los valores sociales. Noelle-Neumann (1995) argumenta que el fenómeno televisivo disminuye la capacidad selectiva, produciéndose la llamada "espiral del silencio". Las personas tienden a prestar mucha atención a las opiniones dominantes y mayoritarias para evitar reducir las disonancias con el entorno y evitar el aislamiento, replegándose en el silencio de la minoría (Monzón, 1996). Esta teoría considera que los efectos de los medios de comunicación son a largo plazo y por esto hace una crítica a los efectos limitados (Berrocal, 1993).

Para Rodríguez (2004) el término de la agenda setting se acuña de una manera metafórica para expresar cómo las agendas o temas son considerados relevantes para las audiencias. Se afirma que las personas no sólo reciben información sobre determinados temas o asuntos que ocurren en el mundo a través de los medios de comunicación, sino que también aprenden de ellos la importancia y el énfasis que le deben dar. Al igual que la teoría de la "espiral del silencio", la agenda setting coincide en que la televisión tiene una influencia decisiva en todos los medios, a tal grado que reduce la capacidad selectiva pública. Esto es muy común en los segmentos noticiosos, donde la mayoría sigue un esquema común, tienen los mismos intereses, fuentes, modelos de guiones de producción y los mismos referentes (Monzón, 1996).

McCombs \& Shaw, citados por Dahdah (2004), sostienen que los medios de comunicación son los intermediarios entre la gente y sus líderes y tienen la tarea principal de informar al público sobre lo acontecido. Dicha función es importante para la política, porque con esos elementos de juicio el elector puede evaluar o ignorar a un candidato, valorar las decisiones o indecisiones asumidas por una autoridad, juzgar la gestión o la aplicación de las políticas en un gobierno determinado, ya que se puede decir que tiene un conocimiento más amplio de la realidad política y su entorno, a partir de que todos los poderes están bajo la lupa de un conocimiento mediático (Dahdah, 2004).

Asimismo, McCombs \& Shaw (1972) argumentan que los ciudadanos aprenden nuevas cosas de la gran cantidad de información que reciben diariamente a través de los medios de comunicación. Del mismo modo, este sería el planteamiento central de la teoría de la agenda que sugiere que las personas pueden aprender en proporción directa al énfasis que realizan los medios en torno a los asuntos de la campaña política, el cual se difunde con frecuencia de la aparición de una noticia y en la ubicación y el espacio que ocupa la misma. 


\section{A manera de conclusión}

La comunicación política, ha ido creciendo como disciplina y campo de estudio dentro de las ciencias políticas modernas. En América Latina es incuestionable su auge y desarrollo, en especial en los procesos electorales después de la alternancia a la democracia, desde 1989, donde se consolidan las campañas electorales, las nuevas tecnologías de la información, la aparición de nuevos partidos políticos, los movimientos sociales y el auge de los políticos outsider.

Dicho auge ha generado una serie de cambios en los programas de ciencias políticas, los cuales han decidido profundizar en el estudio técnico. Se debe concluir que el contenido de la comunicación política es rico en enseñanzas para precisar el funcionamiento de las instituciones, ya que permite que los ciudadanos se forman una idea de estas, las cuales nacen de una presentación del sistema político a través de los discursos (Restrepo-Echavarría, 2018) que se generan en las nuevas formas de la política moderna.

En una democracia, se lucha por derechos, libertades y cumplimiento de las reglas establecidas para el buen funcionamiento del sistema político. La democracia se da espacio a la participación de los ciudadanos para la toma de decisiones; se confrontan las opiniones y la población toma parte de ese debate de posturas sobre las ideas expuestas, para que juntos, población y gobierno, generen un consenso sobre lo que mejor convenga a ambas partes (Reyes, O’Quínn, Morales \& Rodríguez (2011).

En este sentido, se puede concluir que la comunicación política actúa en un universo de diferencias y desigualdades, donde las posiciones de poder condicionan ampliamente el control de los recursos de la comunicación y la elaboración de estrategias. De igual manera se puede determinar que el avance de la comunicación política es inversamente proporcional a la decadencia de las instituciones políticas, el discurso político con carga ideológica y la lucha por la hegemonía.

En consecuencia, la comunicación política es un fenómeno que busca poner en situación hegemónica a un individuo o a un grupo con respecto a los demás grupos de su interés, donde a partir de lo que Gerstlé (2005) denomina un "discurso de media céntrico", donde la comunicación política se convierte 
en el centro de estudio a partir que el discurso político y la vida política no se conciben sin los medios de comunicación y la influencia de la opinión pública, dejando a un lado el deber ser de la democracia pluralista y abierta.

\section{Fuentes consultadas}

Abal, J. (2004). Los partidos políticos. ¿Un mal necesario? Buenos Aires: Capital Intelectual.

Arendt, H. (1969). Philosophy and Politics. What is Political Philosophy? Washington, DC: Library of Congress.

Aristóteles (2004). Retórica. Madrid: Alianza Editorial.

Berrocal, S. (1993). Comunicación política y televisión. Definición de un marco teórico en la investigación electoral en televisión. Las elecciones legislativas 1993 (tesis doctoral). Universidad Complutense de Madrid, España.

Blake, R. \& Haroldsen, E. (1975). Taxonomía de conceptos de comunicación. México, DF: Nuevomar.

Blumer, J. (1999). Tendencias de la comunicación política en las campañas electorales británicas. En A. Muñoz-Alonso \& J. Rospir (Eds.), Democracia mediática y campañas electorales. Barcelona: Ariel.

Bouza, F. (2004). El área de impacto de la comunicación política: La ciudadanía ante el discurso público. International Review of Sociology, 14(2), 245-259.

Caballero, M., De Echano, J., Martínez, E., Montarelo, P. \& Navlet, I. (Cols.) (2001). Historia de la filosofía Noesis: los sofistas y Aristóteles. Madrid: Vicens Vives.

Campbell, A., Converse, P., Miller, W. \& Stokes, D. (1960). The American Voter. Chicago: University of Chicago. 
Canel, M. (2006). Comunicación política, una guía para su estudio y práctica. Madrid: Tecnos.

Chaffee, S. (1981). Mass media in political campaigns: An expending role. En R. Rice \& W. Paisley (Eds.), Public Communication Campaigns (pp. 181-198). Beverly Hills: Sage.

Cicerón (2014). Brevario de campaña electoral. Barcelona: Acantilado.

Cotarelo, R. (2010). La política en la era de Internet. Valencia: Tirant lo Blanch.

Cotteret, J. (1997). La comunicación política. Gobernantes y gobernados. Buenos Aires: El Ateneo.

Dahdah, S. (2004). Mirando al mundo desde las ventanas de un edificio: la comunicación política y sus propuestas teóricas. Politeia, 32/33, $3-40$.

Debray, R. (1995). El Estado seductor: las revoluciones mediológicas del poder. Buenos Aires: Manantial.

Fernández, A. (1996). La renovada centralidad del concepto de poder en la ciencia política de los años noventa. En S. Gaveglio (Ed.), Desarrollos de la teoría política contemporánea. Rosario: Homo Sapiens.

Ferry, J. \& Wolton, D. (1992). El nuevo espacio público. Barcelona: Gedisa.

Figueroa, R. (2013). Introducción a las teorías de la comunicación. México, DF: Pearson.

García, V., D’Adamo, O. \& Slavisky, G. (2011). Propaganda gubernamental. Tácticas e iconografías del poder. Buenos Aires: La Crujía.

Gerstlé, J. (2005). La comunicación política. Santiago de Chile: LOM Ediciones.

Habermas, J. (1981). Historia y critica de la opinión pública. Barcelona: Gustavo Gili. 
Katz, E., Blumler, J. \& Gurevith, M. (1974). Uses of Mass Communication by Individual. En M. de Moragas (Ed.), Sociología de la comunicación. Volumen II: Estructura, funciones y efectos (127- 172). Barcelona: Gustavo Gili.

Kotler, P. (1999). Political Marketing Generating Effective Candidates, Campaigns, and Causes. En B. Newman (Ed.), Handbook of Political Marketing (pp. 3-18). California: Sage Publications.

Lasswell, H. (1938). Propaganda Technique in the World War. Nueva York: Peter Smith.

Lazarsfeld, P., Berelson, B. \& Gaudet, H. (1944). The People Choice: How the Voter Makes Up His Mind in a Presidential Campaign. Nueva York: Universidad de Columbia.

Lazarsfeld, P., Berelson, B. \& McPhee, W. (1954). Voting. A study of opinion formation in a presidential campaign. Chicago: The University of Chicago Press.

Lippmann, W. (2003). La opinión pública. Madrid: Cuadernos de Langre.

Mancini, P. (1995). Americanización y modernización. Breve historia de la campaña electoral. En A. Muñoz-Alonso \& J. Rospir (Eds.), Comunicación política (pp. 141-168). Madrid: Editorial Universitas.

Martín, L. (2002). Marketing político: arte y ciencia de la persuasión en democracia. Barcelona: Paidós.

Martín-Barbero, J. (2005). Los oficios del comunicador. Revista Co-herencia, 2(2), 115-143. Recuperado de http://publicaciones.eafit.edu.co/ index.php/co-herencia/article/view/621

Mazzoleni, G. (2010). La comunicación política. Madrid: Alianza Editorial.

McCombs, M. \& Shaw, D. (1972). The Agenda-Setting Function of Mass Media. The Public Opinion Quarterly, 36(2), 176-187. 
Monzón, C. (1996). Opinión pública, comunicación y política. La formación del espacio público. Madrid: Tecnos.

Noelle-Neumann, E. (1995). La espiral del silencio. Opinión pública: nuestra piel social. Barcelona: Paidós.

Pasquino, G. (1990). Liderazgo político y comunicación política. Psicología Política, 1, 65-85. Recuperado de https://www.uv.es/garzon/psicologia\%20politica/N1-3.pdf

Restrepo-Echavarría, N. (2018). La profesionalización de las campañas electorales en Colombia: elecciones presidenciales 1994-2014 (tesis doctoral). Universidad Complutense de Madrid, España. Recuperado de http://eprints.ucm.es/47843/1/T39975.pdf

Reyes, M., O’Quínn, J. Morales, J. \& Rodríguez, E. (2011). Reflexiones sobre la Comunicación Política. Espacios públicos, 14(30), 85-101. Recuperado de https://www.redalyc.org/pdf/676/67618934007.pdf

Rocha, F. (2007). La profesionalización de las campañas electorales en Brasil (tesis doctoral). Universidad de Salamanca, España. Recuperado de https://gredos.usal.es/bitstream/handle/10366/18601/ DDPG_Profesionalizacion\%20de\%20las\%20campanas\%20electorales.pdf;jsessionid=34C9D995F0D164C2CAFF1A721D1C5BFF?sequence $=1$

Rodríguez, R. (2004). Teoría de la agenda-setting: aplicación a la enseñanza universitaria. Recuperado de https://rua.ua.es/dspace/bitstream/10045/2297/1/Agenda_Setting.pdf

Sartori, G. (1998). Homo Videns. La sociedad teledirigida. Madrid: Taurus.

Sartori, G. (2005). Videopolítica. Medios, información y democracia de sondeo. México, DF: Fondo de Cultura Económica.

Swanson, D. \& Mancini, P. (Eds.) (1996). Politics, Media and Modern Democracy. An International Study of Innovations in Electoral Campaigning and their Consequences. Connecticut: Praeger. 
Vallejo, L. (2009). Reflexiones sobre el campo de la comunicación. Bogotá: Manuskripta.

Wolton, D. (2012). La comunicación política. Construcción de un modelo. En AA. VV., Comunicación política (pp. 27-48). Buenos Aires: La Crujía. 